\title{
An integrated approach to study of strata behaviour and gas flow dynamics and its application
}

\author{
Hua Guo ${ }^{1} \cdot$ Liang Yuan ${ }^{2}$
}

Received: 5 March 2015/Revised: 25 March 2015/Accepted: 26 March 2015/Published online: 1 May 2015

(C) The Author(s) 2015. This article is published with open access at Springerlink.com

\begin{abstract}
This paper presents an advanced and integrated research approach to longwall mining-induced strata movement, stress changes, fractures, and gas flow dynamics with actual examples of its application from recent studies for coextraction of coal and methane development at Huainan Mining Group in China, in a deep and multi-seam mining environment. The advanced approach takes advantage of the latest techniques in Australia for mine scale geotechnical characterisation, field measurement, monitoring and numerical modelling. Key techniques described in this paper include coal mine site 3D geotechnical characterisation methods, surface deep downhole multi-point extensometers and piezometers for overburden displacement and pore pressure measurements during mining, tracer gas tests for goaf gas flow patterns, and advanced numerical modelling codes for coupled coal mine strata, water and gas simulations, and longwall goaf gas flow investigations. This integrated approach has resulted in significant insights into the complex dynamic interaction between strata, groundwater, and gas during mining at Huainan Mining Group in recent years. Based on the findings from the extensive field monitoring and numerical modelling studies, a three-dimensional annular-shaped overlying zone along the perimeter of the longwall panel was identified for optimal methane drainage during mining.
\end{abstract}

Keywords Co-extraction of coal and gas - Strata behaviour - Pore pressure - Gas flow - Annular overlying zone . COSFLOW · CFD

\section{Introduction}

Coal mine methane (CMM) is released from coal and surrounding rock strata during underground mining activities. The primary concern of methane in underground mines has been personnel safety due to potential explosion on hazards; however, CMM is also a significant source of clean energy. Any CMM not captured and used will be released into the atmosphere, not only contributing significantly to fugitive greenhouse gas (GHG) emissions, but also becoming a wasted energy resource.

Hua Guo

hua.guo@csiro.au

1 The Commonwealth Scientific and Industrial Research Organisation, PO Box 883, Kenmore, QLD 4069, Australia

2 Huainan Mining (Group) Co., Ltd., Huainan 232001, China
The concept and practices of integrated coal production and methane extraction (Guo et al. 2001, 2012; Qian and Shi 2003; Cheng et al. 2004; Yuan 2004, 2008; Xie et al. 2014) have emerged in recent years as an effective way of improving coal mining safety and productivity, using coal seam methane resources, and reducing fugitive emissions in situations that involve multiple coal seams with low gas permeability. This co-extraction system integrates two previously separate operations: coal extraction and methane drainage as shown in Fig. 1. The coal mining operation reduces coal seam gas pressure and also creates fractures in the surrounding strata that enhance gas capture from the longwall workings and surrounding coal seams. An effective methane drainage operation produces a consistent and quality clean-energy product, while reducing methane concentration in the underground workings and methane content and pressure in the adjacent coal seams. Effective co-extraction provides a significant benefit in 


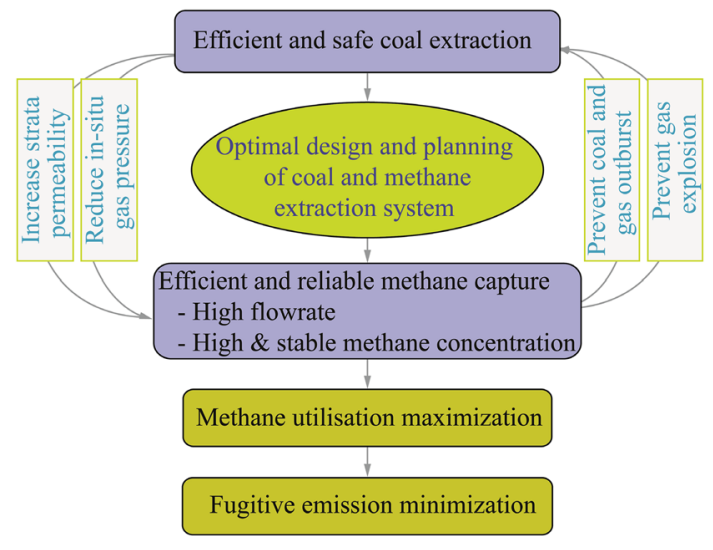

Fig. 1 Co-extraction system of coal and methane

preventing gas explosions and outbursts and promotes a safer, more productive coal mining environment. In addition, recovering and utilising CMM directly reduces GHG emissions.

To realise the full potential from co-extraction of coal and methane, coal mines require a holistic and optimal approach of planning, design and operational control of coal mining and methane drainage and ventilation systems to maximise coal mining productivity and methane capture performance, and minimise fugitive emissions in gassy and multiple seam conditions. This in turn requires a detailed understanding of mining induced strata movement, ground water and gas flow dynamics, and the interaction between goaf gas, drainage and mine ventilation.

To date, extensive studies in these areas have been carried out for various purposes such as mine ground control, water inrush prevention, and gas control, respectively. Front and side abutment stresses around a longwall (LW) panel, de-stressing behind the coal face, and goaf consolidation processes have been investigated and characterised by many researchers. Overburden strata fractures are generally classified into various zones vertically (Peng and Chiang 1984; Qian et al. 2003), such as the caved zone, the fractured zone, and the continuous deformation zone (Qian et al. 2003). Extensive strata fractures at a LW panel caused by mining were located and characterised as, for example, the "O"- shaped fracture zone (Qian and Xu 1998). For the purpose of gas drainage, mining induced fractures were characterised into various types and each of them was identified in the overburden for appropriate gas drainage design (Yuan 2004). LW goaf gas flow dynamics has been investigated by many researchers using various methods such as gas tube bundle systems, underground tracer gas tests, and computational fluid dynamics (CFD) numerical modelling techniques for gas drainage, as well as fire control. To understand the spatial distribution of goaf gas concentration and pressure, CFD has been used to improve the design and operation of goaf gas wells and goaf inertisation (for heating control) (Balusu et al. 2005; Yuan and Smith 2007). Methane emissions from various sections of a vertical borehole were measured to identify the height of the interconnected fracture zone (Palchik 2003, 2005).

These studies have contributed to improved understanding of complex coal mine gas flow mechanisms in recent years. However, to integrate and optimise coal extraction and methane drainage design, particularly in the multiple coal seam environment with low permeability which is common in China, it is important to understand the dynamic interaction between strata, water, and gas desorption and migration during mining in a large scale as shown in Fig. 2. To carry out this research that supports optimal co-extraction of coal and methane, a new research approach is required. Such an approach should include reliable site geotechnical characterisation, large scale field monitoring techniques that simultaneously measure and monitor LW mining-induced strata movement, stress changes, fractures, and gas flow behaviours, and 3D numerical modelling techniques that simulate coupled behaviours of surrounding strata, groundwater and gas during mining.

Over the last 15 years, CSIRO has developed an integrated approach to coal mine methane research. The central part of this approach is state of the art techniques for site geotechnical characterisation, field monitoring, and numerical modelling, as well as a full integration of strata, groundwater and gas studies. Examples of these techniques are presented as follows.

In this study, we examined the influences of precipitators and desulfurization equipment on particle emission characteristics in the flue gas cleaning system. The particle size distributions before and after four different dust

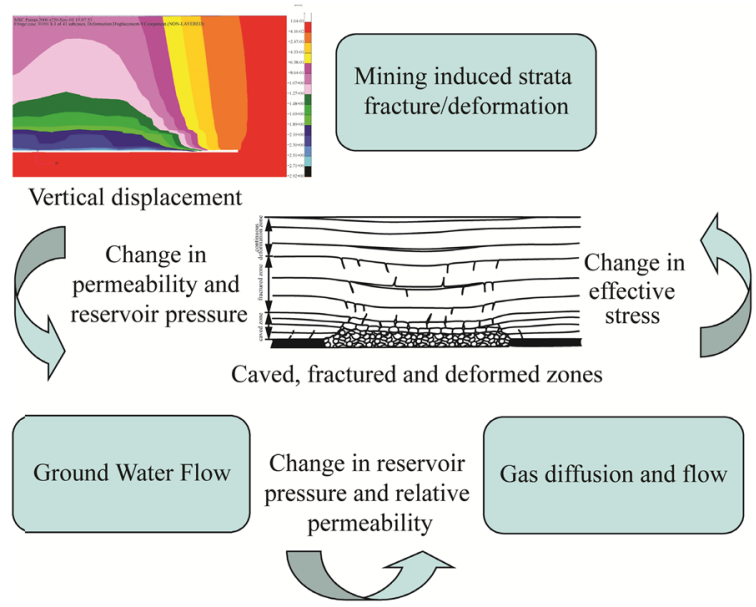

Fig. 2 Complex interaction between rock mass deformation and water/gas flow during LW mining 
removal devices in six coal-fired power plants were measured, including the hybrid ESP/BAGs that have not been measured previously. The influence of different dust removal devices on $\mathrm{PM}_{2.5}$ emission characteristics was also analyzed. The measurement data derived from power plants were accumulated to provide the basis for the choice of $\mathrm{PM}_{2.5}$ control technology. In particular, the influence of hybrid ESP/BAG operating conditions on dust removal performance was explored. The concentrations and distributions of particulate matter before and after desulfurization devices were also measured in three coal-fired power plants. The results were used to analyze the cleaning effect of wet desulfurization devices on $\mathrm{PM}_{2.5}$. The findings of this study can provide a reference for the use of wet flue gas desulfurization (WFGD) technology in removing fine particles in flue gas.

\section{Integrated research approach and techniques}

\subsection{Site geotechnical characterisation}

Accurate assessment of mining-induced strata changes is an essential step towards understanding coupled strata, groundwater and gas behaviours, which depends on reliable site geotechnical conditions. Conventionally, geotechnical information comes from cored drill holes. However, coring is expensive and most boreholes are drilled with no or very limited coring. Alternative ways of obtaining geotechnical information needs to be found. One approach is to use geophysical logging. Borehole geophysical logging is carried out routinely at coal mines. Logging measures various in situ petrophysical parameters which are usually correlated with rock types and can be also used for rock mass characterisation.

An automated geotechnical characterisation method from geophysical logs was initially developed to identify the key strata responsible for caving behaviours during LW coal mining at Southern Colliery in Central Queensland, Australia (Guo et al. 2000). The method is based on a computer program LogTrans developed by Centre for mining technology and equipment (CSIRO/CMTE) for geological interpretation. Conventional logs such as density, natural gamma and UCS (derived from sonic transit time) logs were utilised. A 3D geotechnical model of the study area of the Colliery was established using Vulcan (a trade mark software) based on the LogTrans interpretation.

This method was further developed and applied to the Wambo Colliery, Australia for the overburden geotechnical characterisation of the entire site using Vulcan. Borehole geotechnical interpretation using LogTrans involved the following key steps:
(1) Detailed analysis of key control cored holes where geotechnical logs, core photograph, and rock strength testing results are available to set up strata classification criterion for various key strata units.

(2) Statistical characterisation of geophysical signatures of these strata units using LogTrans.

(3) Automatic computer interpretation of geophysical logs of other open holes for the geotechnical units using the identified geophysical signatures.

The geotechnical units predicted from the geophysical logs, as shown in Fig. 3 (Guo et al. 2008a, b), were well matched with the original strata classification.

Vulcan was also used to create a 3D geotechnical model as well as for sedimentary modelling at Wambo Colliery. The advantages of using the same modelling software and procedures for both tasks include greater consistency in coal picking and reduced duplication during data preparation and processing. The resulting 3D geotechnical model,

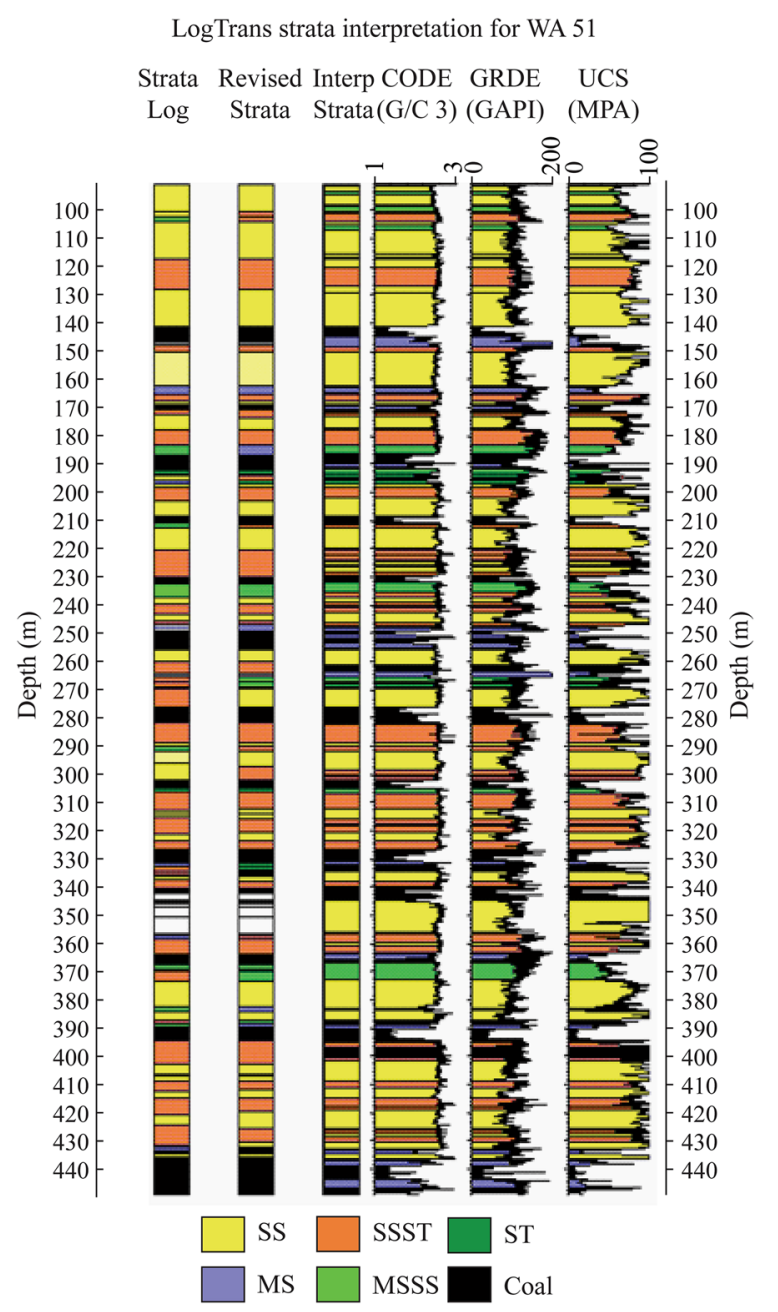

Fig. 3 Interpreted strata units (the third column) from borehole geophysical logging data 


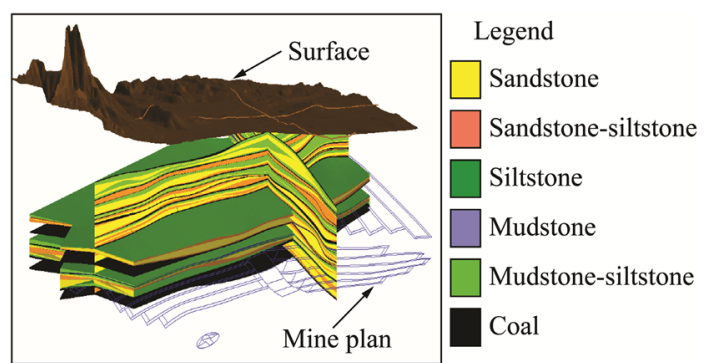

Fig. 4 Perspective view of 3D geotechnical model of a mine site in Australia

as shown in Fig. 4 (Guo et al. 2006), can be sectioned at any orientation or analysed by isopachs and can have particular units contoured for depth, thickness or other attributes.

\subsection{Deep downhole multi-anchor extensometers}

A deep downhole extensometer system uses high tensile stainless steel wires connected to spring anchors mechanically placed in the borehole. At the collar, these wires are connected to spring loaded sensors in a head frame. This provides a physical means of measuring the displacement in key overburden strata layers between workings and the surface. Up to 20 anchors can be placed in one hole.

An application of these deep downhole extensometers to study LW overburden movement during mining at West Cliff Colliery, Australia, is shown in Fig. 5 (Shen et al. 2010). The extensometer borehole was drilled to $420 \mathrm{~m}$ depth at the panel centre of LW 32. A total of 20 anchors were installed to monitor major bed separations which occurred at the interfaces between different rock units above the Bulli seam (the mining seam). The extensometer monitoring commenced when the LW underground mining face was $750 \mathrm{~m}$ away from the borehole. Figure 6 shows the measured overburden movement of various anchors till the LW face passed the borehole location by $900 \mathrm{~m}$.

\subsection{Deep downhole vibrating wire piezometers}

Vibrating wire (VW) piezometers are designed to measure fluid or pore-water pressures in a variety of geotechnical applications. The VW piezometer incorporates a vibrating wire pressure sensor enclosed inside a stainless steel housing. The VW sensing element is formed essentially of a steel wire clamped under tension between a sensitive diaphragm at one end and the rear body of the transducer at the other. An electromagnetic coil (in the sensor) is used to excite the wire to vibrate (ring) and then to measure the vibration frequency of the wire. The measured frequencies vary accurately in accordance with the calibrated values

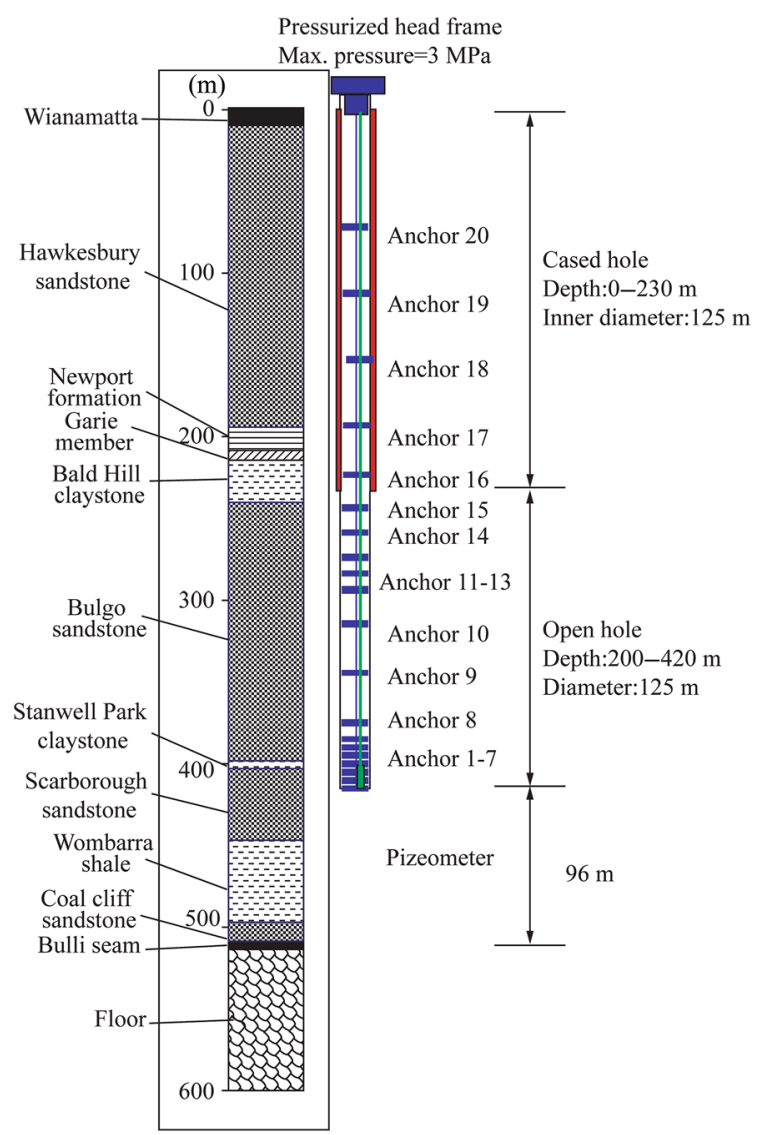

Fig. 5 Characteristics and instrumentation methods of the extensometer borehole, showing borehole $\log$ (left), positions of extensometer anchors

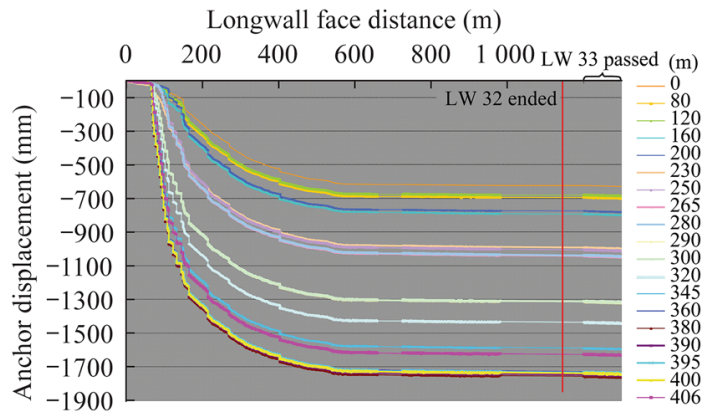

Fig. 6 Measured strata and surface subsidence versus the distance of LW face past the monitoring borehole location from extensometer measurements

between frequency and applied pressure on the diaphragm element of the sensor.

The change in pore pressure in the surrounding strata during mining has a direct link with the type of strata fractures, making it possible to estimate the extent of various fracture zones by measuring water pressure changes. An actual example of measured water pressure change 
at Panel 1115(1) of the Guqiao Mine, Huainan Mining Group (HMG), and associated overburden strata layers are shown in Fig. 7 (Guo et al. 2012). The key observations from the measurement results were as follows.

The strata with a significant water pressure drop can extend up to $145 \mathrm{~m}$ (48 times of mining thickness) above the working seam, indicating that the zone of strata fractures has extended to this height. Strata at different heights showed a different trend in water pressure change, indicating the effect of mining-induced strata stress changes and rock fracturing. It is postulated that the roof strata within 7-43 m (2-14 times of mining thickness) have been fractured vertically or subvertically, and that the fractures are linked hydraulically between different strata layers. This zone can be called the cross-strata fracturing zone. Within the height range of $88-145 \mathrm{~m}$ (29-48 times of mining thickness) is the bed separation zone where fractures, mainly horizontal, developed. At a height of 145-237 m (48-79 times of mining thickness), rock mass deformed continuously without significant fracturing. This zone is commonly referred as the deformation zone. Further up in the alluvium layers, the key aquifers were not affected by mining.

Laterally, at the mining level, the water pressure started to increase at a distance of $300 \mathrm{~m}$ ahead of the LW face, indicating that mining induced stress can extend to $300 \mathrm{~m}$ ahead. Water pressures dropped rapidly between $100 \mathrm{~m}$ ahead of the LW face and $170 \mathrm{~m}$ behind the LW face, implying that mining-induced strata fractures and stress changes are developed within this region. Further behind the LW face the water pressure was either stabilised or started to recover, suggesting that the goaf is being consolidated and the mining induced fractures are being compacted in this zone.

\subsection{Tracer gas tests for goaf gas flow patterns}

In addition to the common tube bundle systems used to measure goaf gas conditions, tracer gas techniques have been used by CSIRO in recent years to investigate gas flow patterns in active LW goafs. Tracer gas investigations were carried out to provide more insight into the gas flow dynamics in LW goafs. Sulphur hexafluoride (SF6) gas is often used as tracer gas in these field studies. The studies basically involve releasing tracer gas into the goaf at the designated point and collecting gas samples at various locations in and around the LW goaf at varying time intervals.

An example of a tracer test at a coal mine in Australia is shown in Fig. 8. In this study, tracer gas first arrival times and gas levels were measured at various monitoring locations around the LW goaf. Analysis of the results shows that airflow/oxygen migrates very deep into the goaf on the intake side of the panel, depending on panel geometry and ventilation conditions. Tracer gas was detected at sampling points located at $150 \mathrm{~m}$ behind the face within $2 \mathrm{~min}$ and at $1000 \mathrm{~m}$ behind the face within $1 \mathrm{~h}$.

It was noted that all three goaf drainage holes behind the face recorded certain levels of tracer gas concentration,

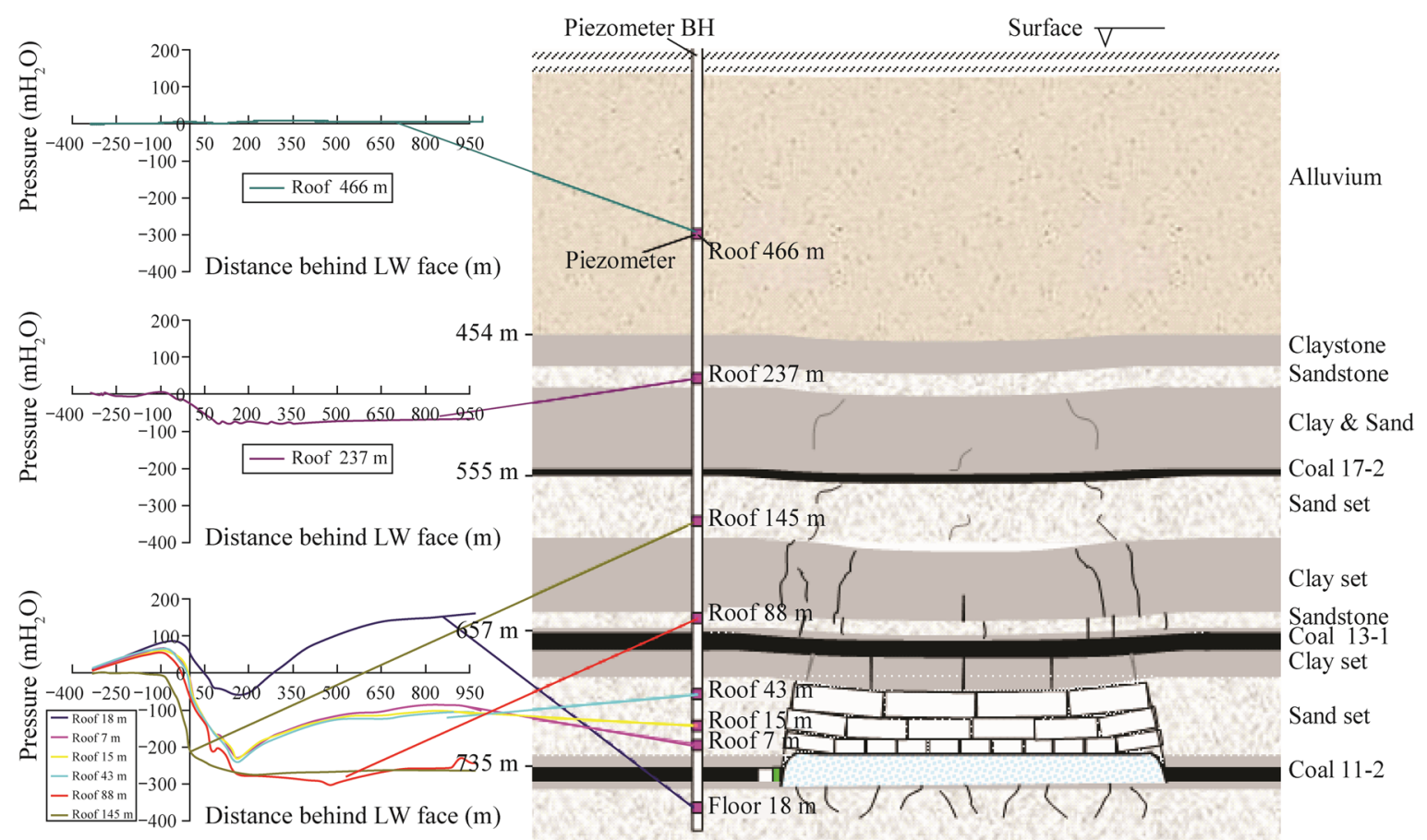

Fig. 7 Measured water pressure change and its relationship with rock fracturing characteristics 


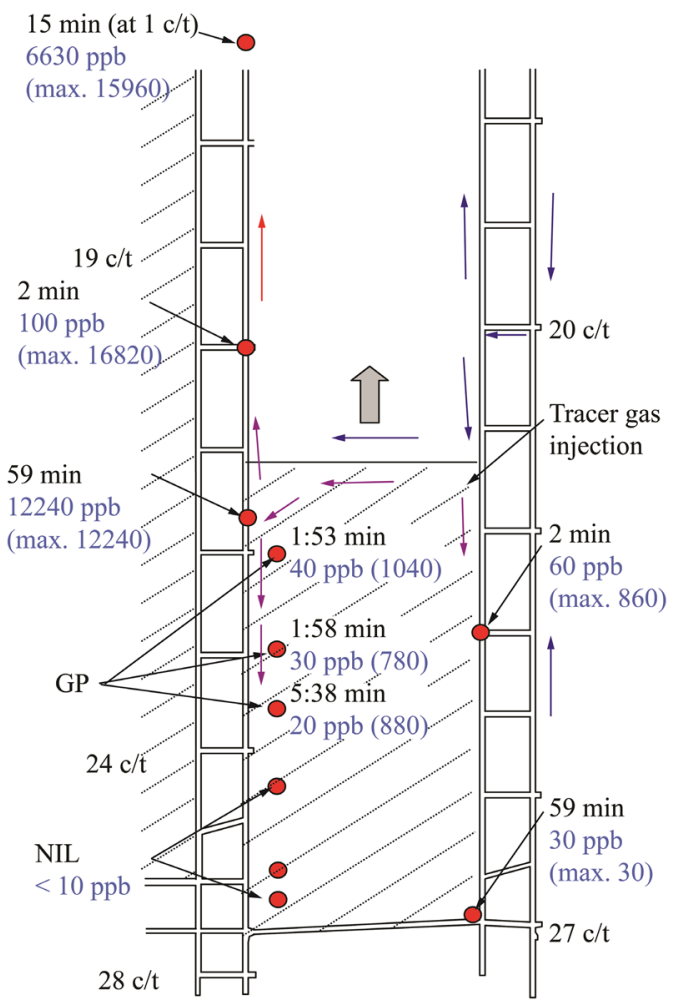

Fig. 8 Tracer gas first arrival times at different locations in the goaf at a mine

even though it took $4 \mathrm{~h}$ for the tracer gas to reach the third goaf hole. These results indicate that even the goaf drainage holes located far behind the face help to keep the gas away from the face. The results also indicate that the goaf at $200-250 \mathrm{~m}$ behind the face is highly consolidated and does not allow direct travel of tracer gas from the intake side to the return side.

\subsection{COSFLOW}

Rock strata in a coal mining environment are essentially bedded and this has a large impact on load-deformation characteristics. Mining may induce shearing as well as separation along the bedding planes, which may result in bending and subsequent fracturing of the rock layer. This on the other hand may substantially change the in situ fluid or gas flow properties of the rock mass, such as permeability and porosity. Thus a proper coupling of mine induced deformation, fluid flow properties and the process of fluid flow itself is a must for any reliable modelling of rock mass deformation, water and gas flow into a coal mine.

COSFLOW is a three dimensional finite element code, developed by CSIRO, and the New Energy and Industrial Technology Development Organization (NEDO), and the Japan Coal Energy Centre (JCOAL), of Japan (Guo et al.
2009). COSFLOW simulates the complex behaviour of rock, water and gas flow, and predicts gas emission during LW development and retreat. The code is also capable of simulating gas drainage performance and estimating gas production.

A unique feature of COSFLOW is the incorporation of Cosserat continuum theory in its formulation. In the Cosserat model, inter-layer interfaces are considered to be smeared across the mass, i.e., the effects of interfaces are incorporated implicitly in the choice of stress-strain model formulation. An important feature of the Cosserat model is that it incorporates bending rigidity of individual layers in its formulation and this makes it different from other conventional implicit models. In comparison with the conventional continuum model which has three independent degrees of freedom and six independent stress components in a three dimensional case, the Cosserat model for the stratified material will have six independent degrees of freedom and 10 independent stress components. The layer interfaces can exhibit three different modes of behaviour: (a) elastically connected with the interface normal and shear stiffness, (b) plastic with frictional sliding and (c) disconnected with tensile opening. Similarly the rock layer may either deform elastically or may sustain some plastic deformation as well.

In COSFLOW, a porous medium is simulated as a region having two porosities; one representing a continuum porous rock (primary porosity) and the other representing a fracture network (secondary porosity). Thus, the flow behaviour is mainly described by the interaction of the basic components, namely the porous matrix and the surrounding fracture system. The fractures provide rapid hydraulic connection but little fluid mass storage, whereas the porous matrix represents high storage but low hydraulic connection. The flow model incorporated in COSFLOW is similar to the conventional flow model; i.e. the flow in the fracture (cleat) system is controlled by the pressure gradient and is described using Darcy's law, whereas, the desorption (flow in the matrix) is controlled by the concentration gradient and is described using Fick's law. The relationship between gas concentration and pressure is a non-linear function and is described using Langmuir equations.

In order to be able to correctly estimate water inflow or gas emissions, it is important not only to estimate the initial permeability correctly, but also to compute its variation during mining. In this code, permeability change during mining is computed as a function of the mining induced strain (Adhikary and Guo 2014).

Figure 9 shows an example of the COSFLOW model for the Guqiao mine of HMG, constructed from a 3D geological model with 136 borehole logs. It simulates a relatively large area of $10000 \mathrm{~m}$ long, $9000 \mathrm{~m}$ wide and 


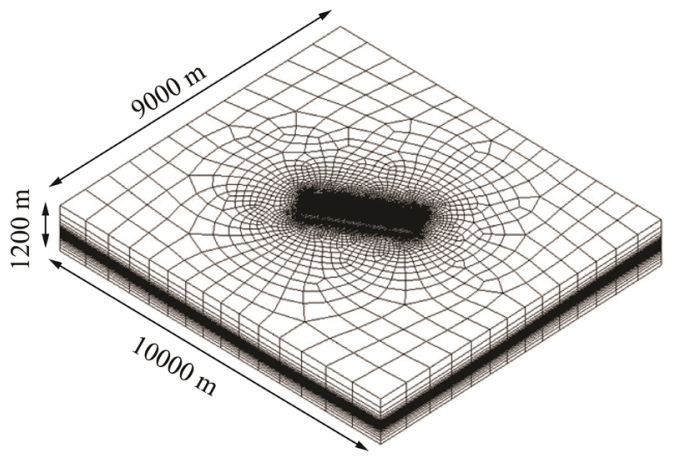

Fig. 9 COSFLOW model and mesh for Guqiao mine

$1200 \mathrm{~m}$ deep, with 1245951 elements. The mine was subject to deep mining condition with a depth of over $735 \mathrm{~m}$. Figure 10 shows the modelled vertical strata destressing in and about the LW panel. Key observations regarding with strata de-stressing and permeability changes from the COSFLOW modelling results are as follows.

(1) Along the panel length direction, the vertical stress shows a 4-stage process marked by increasedecrease-recovery-stabilisation. The highly stress reduction zone is $0-80 \mathrm{~m}$ behind the face, followed by a stress recovery zone around 150-200 m behind the face. Beyond $200 \mathrm{~m}$ the stress begins to stabilize.

(2) Across the panel, the vertical stress in the central part of the panel recovers gradually as the mining retreats. However, a de-stressed zone remains at either side of the panel even after the completion of the mining.

(3) A horse-saddle shaped horizontal permeability distribution is predicted across the panel width, where the permeability in strata above the panel's central region is predicted to increase, decrease, and finally stabilise as the face advances. In a plan view, an annular region with high permeability can be seen.

\subsection{Computational fluid dynamics (CFD) mine gas flow modelling}

To determine appropriate gas control strategies and design optimal drainage boreholes, it is essential to understand the gas flow mechanisms and gas distributions in the goaf and the ventilation system. Gas flows in the LW goaf are complex and contain multiple components including methane, oxygen, nitrogen, and carbon dioxide, etc. These different components may come from different sources such as various overlying and underlying coal seams, gas bearing strata units, and worked goafs. Mining induced gas flows are a combined consequence of geomechanical

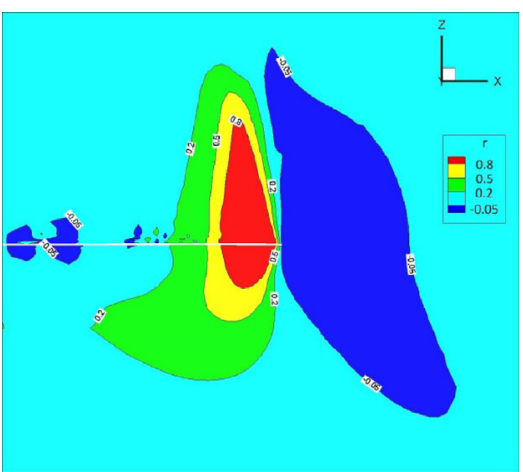

(a) Stress distribution in a vertical cross section along the length of the panel

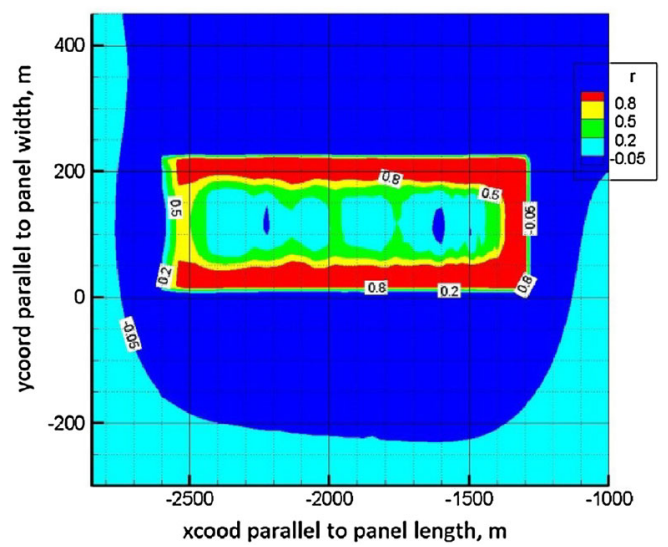

(b) Stress distribution in a plane section $30 \mathrm{~m}$ above the mining seam

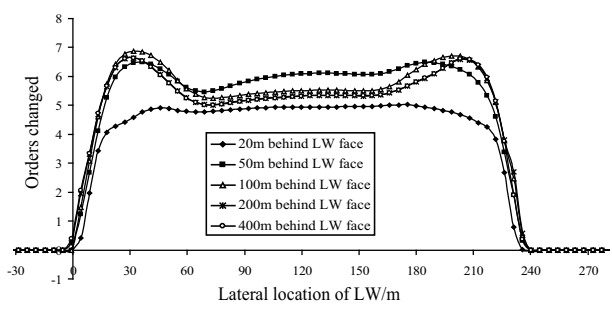

(c) Horizontal permeability changes across the panel width $30 \mathrm{~m}$ above the working seam

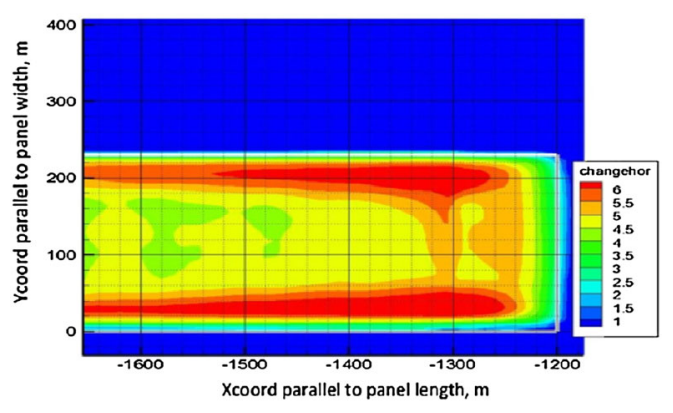

(d) Distribution of horizontal permeability changes in a plane section $30 \mathrm{~m}$ above the working seam

Fig. 10 Modelled strata de-stressing and permeability changes during LW mining 
changes and associated gas reservoir condition changes, mine ventilation, and gas drainage.

To understand the gas flow processes, 3D computational fluid dynamics (CFD) models have been developed to study the goaf gas dynamics under the influence of various mining and geological parameters including ventilation layouts, face orientation and gas emission rates. CFD simulations have been used in the investigation of gas flow migration dynamics within LW goaf areas with the objective of improving gas capture, minimising the risk of spontaneous combustion and developing effective goaf inertisation strategies.

Figure 11a shows the constructed CFD model for Guqiao mine. Flow parameters and boundary conditions set in the model were based on the site monitoring data and the geomechanical modelling results with COSFLOW. The commercial CFD software Fluent was employed to conduct the CFD simulation. The modelled methane concentration increases with the height, the distance behind the face, and the lateral distance from the panel sides (i.e. roadways). Low methane concentration $(<30 \%)$ exists in the vicinity of the LW face and the roadways, as shown in Fig. 11b.

Figure 12 shows an example of the modelled gas flow pattern when drained from a vertical borehole in the goaf. It is seen that gas flows mainly along the perimeter of the goaf zone, where the strata de-stressing is maintained, and gas released from the adjacent coal seam flows horizontally at first to the perimeter of the goaf zone and then flows through the annular flow channels.

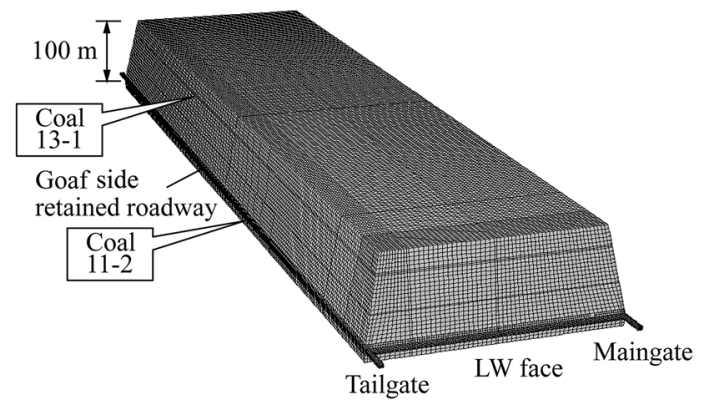

(a) A CFD model for Guqiao mine

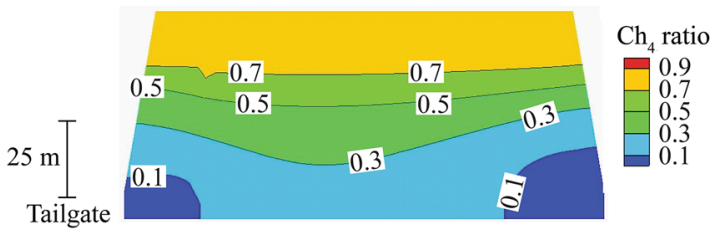

(b) Methane concentration distribution in a cross-section

Fig. 11 The CFD model for Guqiao mine and the modelled methane concentration distribution around the LW panel

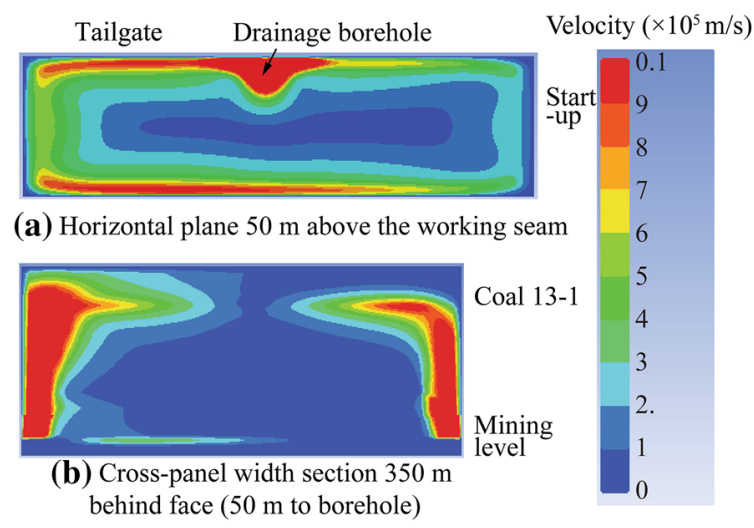

Fig. 12 Modelled gas flow pattern under drainage condition

\section{$3 \mathrm{AOZ}$ for co-extraction of coal and coal mine methane}

Over the last decade, CSIRO and HMG in China have completed several major collaborative research projects to study coupled behaviours of mining induced strata, groundwater and gas to support co-extraction of coal and methane planning and design in various mining conditions at HMG, including Guqiao, Xieyi, Pansan, and Zhuji. In these studies, CSIRO and HMG have further developed the integrated research approach with extensive field studies. These studies have resulted in significant insights into the complex dynamic interaction between strata, groundwater, and gas during mining at HMG and provided fundamentals to support optimal design and planning for the co-extraction of coal and gas system.

Optimal methane drainage relies on two key factors: constantly high gas flow and high methane concentration. To achieve such goals, the drainage boreholes should be located in the zone with high methane desorption, high permeability, and high methane concentration. Based on extensive studies of the mining induced overburden destressing, permeability distribution, and goaf gas flow processes under drainage and ventilation, a conceptual model, called annular overlying zone (AOZ) as shown in Fig. 13, was developed. AOZ is a three-dimensional overlying channel along the perimeter of the LW panel that is located vertically at the low part of the overburden fractured zone immediately above the goaf that provides a "sweet spot" for goaf gas drainage. In this channel, vertical strata stress is relatively low, and mining induced horizontal permeability is relatively high due to residual bedding delaminations or separations. Drainage boreholes located in this channel allow the drawing of gas from a large lateral area along the goaf perimeter. Drainage boreholes located below this channel may draw excessive mine air that dilutes drainage gas concentration and 


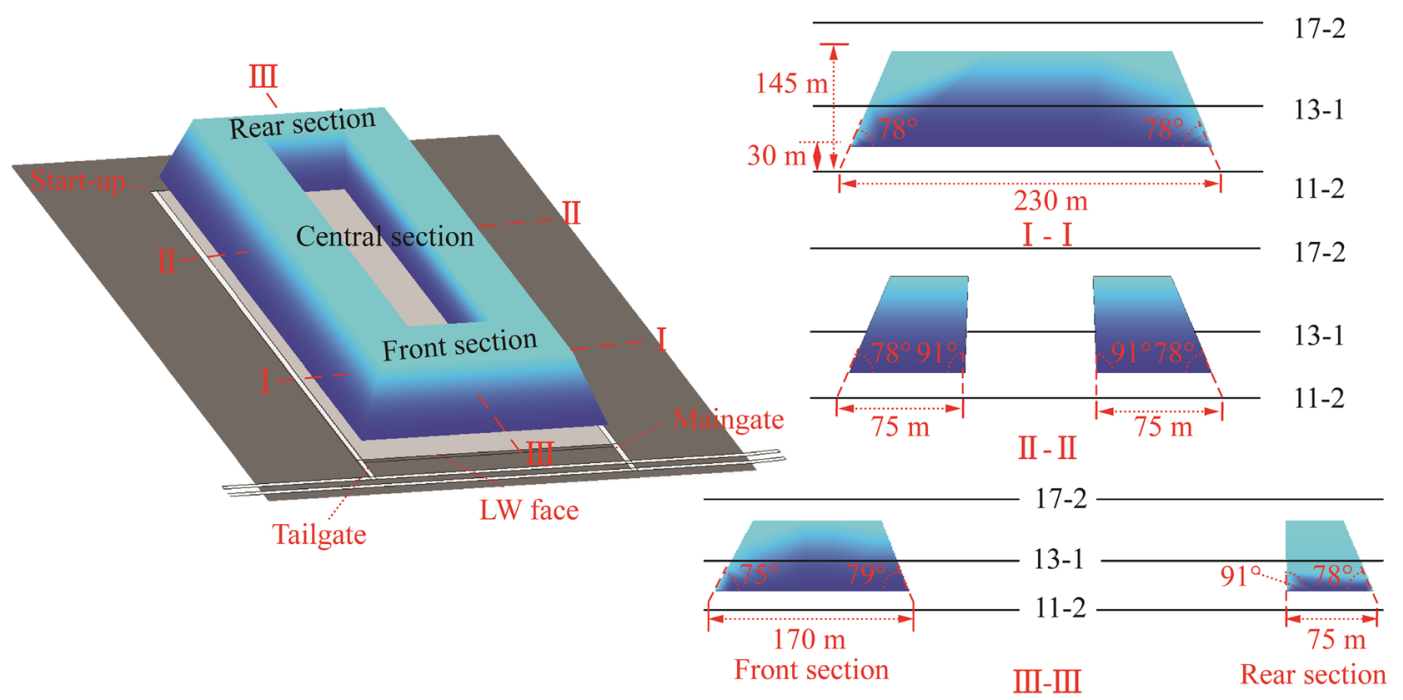

Fig. 13 An earlier conceptual model developed at Guqiao mine: annular overlying zone

efficiency. Where sponcom is an issue, drawing air into the goaf increases heating risks. Drainage holes above the channel are possible to capture high quality gas, particularly where there are overlying gas-producing seams during LW retreat. However, it can have a minimal effect on goaf gas flows and therefore on gas control as the vertical strata fracture connection to the goaf is insufficient.

This conceptual model was successfully applied for optimisation of mining sequence and gas drainage design at coal mines. An example of such applications is the significant improvements achieved in terms of safe working conditions, gas capture efficiency, gas utilisation, and fugitive emission reduction at the Pansan mine where optimisation of both mining sequence and surface goaf drainage wells was involved (Guo et al. 2013). The LW face methane emissions were controlled effectively with surface goaf drainage boreholes located within the AOZ zone.

\section{Conclusions}

Co-extraction of coal and methane requires a detailed understanding of mining induced strata movement, ground water and gas flow dynamics, and the interaction between goaf gas, drainage and mine ventilation. An integrated research approach for co-extraction of coal and methane was therefore developed. It includes a set of complimentary techniques including coal mine 3D geotechnical characterisation, overburden displacement monitoring with surface deep downhole multi-point extensometers, pore pressure monitoring with piezometers, tracer gas tests for goaf gas flow study, simulation of coupled strata, groundwater and gas with the CSIRO's code of COSFLOW, and simulation of goaf gas flow dynamics with advanced CFD code. This approach has been applied successfully to improving mine subsidence management, groundwater and gas control at coal mines in Australia.

The approach was further adopted and developed in recent studies at several coal mines at HMG in China. With this approach, the studies have resulted in significant insights into the complex dynamic interaction between strata, groundwater, and gas during mining. Field monitoring results showed active mining-induced fracturing occurs within $170 \mathrm{~m}$ behind the LW face, and the height of the fractured zone where pore pressure reduces significantly can extend up to $145 \mathrm{~m}$ above the working seam. With extensive 3D site geological characterisation and COSFLOW and CFD modelling work, the spatial shape, location, stress and permeability conditions of the fractured zones at LW panels were obtained, as well as gas flow mechanisms and gas concentration distribution under the influence of mine ventilation, and gas drainage. It was found that drainage efficiency is controlled by three key factors: the degree of de-stressing, permeability distribution, and the pattern of gas flow. It was also found that at the middle and upper part within the fractured zone, there exists an annular gas flow channel along the perimeter of the LW panel, from which high concentration methane can be captured with a relatively high and stable flow rate.

Acknowledgments The research projects mentioned in this paper were supported by a number of organisations in Australia, China and Japan, including HMG, NEDO, JCoal, ACARP, and CSIRO. The authors wish to acknowledge significant contributions to these projects by Dr Baotang Shen, Dr Qingdong Qu, Dr Johnny Qin, Dr Balusu Rao, Dr Deepak Adhikary, and Dr Binzhong Zhou of CSIRO, Mr Ping Li, Mr Binchen Liao, and Junhua Xue of HMG, mine staff and management teams at Guqiao, Xieyi, Pansan and Zhuji mines at HMG. 
Open Access This article is distributed under the terms of the Creative Commons Attribution 4.0 International License (http:// creativecommons.org/licenses/by/4.0/), which permits unrestricted use, distribution, and reproduction in any medium, provided you give appropriate credit to the original author(s) and the source, provide a link to the Creative Commons license, and indicate if changes were made.

\section{References}

Adhikary DP, Guo H (2014) Modelling of longwall mining-induced strata permeability change. Rock Mech Rock Eng 48:345-359

Balusu R, Ren T, Humphries P (2005) Proactive inertisation strategies and technology development, ACARP Project C12020: exploration and mining report No: $907 \mathrm{~F}$

Cheng YP, Yu QX, Yuan L (2004) Experimental research of safe and high efficient exploitation of coal and pressure relief gas in long distance. J China Univ Min Technol 33:132-136

Guo H, Zhou B Z, Poulsen B (2000) 3D overburden geotechnical characterisation for longwall mining at Southern Colliery. In: Beetson JW (ed.) Proceedings of Bowen basin symposium 2000-The New Millennium, Rockhampton, pp 67-72

Guo H, Ishihara N, Fujioka M (2001) Integrated simulation of deep coal seam mining — optimisation of mining and gas management. In: Australia-Japan technology exchange workshop in coal mining 2001, Hunter Valley

Guo H, Adhikary D, Craig MS (2006) Integrated approach to mine water assessment. In: Proceedings of water in mining 2006, Brisbane

Guo H, Adhikary DP, Ishihara N (2008a) Coupled strata and gas behaviour in co-extraction of coal and methane. In: Proceedings of 1 st southern hemisphere international rock mechanics symposium, Perth

Guo H, Balusu R, Adhikary DP (2008b) Coal mine gas drainage and recent developments in Australia. In: Proceedings of China international conference on coal mine gas control and utilisation, Huainan

Guo H, Adhikary DP, Craig MS (2009) Simulation of mine water inflow and gas emission during longwall mining. Rock Mech Rock Eng 42:25-51

Guo H, Yuan L, Shen BT, Qu QD, Xue JH (2012) Mining-induced strata stress changes, fractures and gas flow dynamics in multiseam long wall mining. Int J Rock Mech Min Sci 54:129-139

Guo H, Yuan L, Liang YP, Qu QD, Qin J, Xue S, Xie J (2013) Coextraction of coal and methane. In: Proceedings of 23rd world mining congress, Montreal

Palchik V (2003) Formation of fractured zones in overburden due to longwall mining. Environ Geol 44:28-38

Palchik V (2005) Localization of mining-induced horizontal fractures along rock layer interfaces in overburden: field measurements and prediction. Environ Geol 48:68-80

Peng S, Chiang HS (1984) Longwall mining. Wiley, New York

Qian MG, Shi PW (2003) Control of mine ground pressure and strata. China University of Mining and Technology Press, Xuzhou

Qian MG, Xu JL (1998) Study on the "O-Shape" circle distribution characteristics of mining induced fractures in overlying strata. J China Soc 23:466-469

Qian MG, Xu JL, Miao XX (2003) Green technique in coal mining. J China Univ Min Technol 32:343-348

Shen B, Alehossein H, Poulsen B (2010) Subsidence control using coal washery waste. ACARP project $\mathrm{C} 16023$ final report

Xie HP, Zhou HW, Xue DJ (2014) Theory, technology and engineering of simultaneous exploitation of coal and gas in China. J China Coal Soc 39:1391-1397

Yuan L (2004) Theory and technology of gas drainage and capture in soft multiple coal seams of low permeability. China Coal Industry Publishing House, Beijing

Yuan L (2008) Theory and practice of integrated pillarless coal production and methane extraction in multiseams of low permeability. China Coal Industry Publishing House, Beijing

Yuan L, Smith A (2007) Numerical study on effects of coal properties on spontaneous heating in longwall gob areas. Fuel 87:3409-3419 